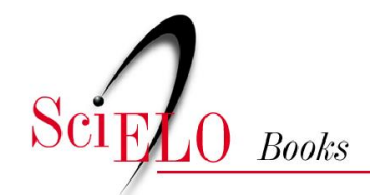

\title{
A virtù do governante maquiaveliano e a tradição das virtudes cristãs
}

\author{
Flávia Benevenuto
}

\section{SciELO Books / SciELO Livros / SciELO Libros}

BENEVENUTO, F. A virtù do governante maquiaveliano e a tradição das virtudes cristãs. In: PINTO, F.M., and BENEVENUTO, F., comps. Filosofia, política e cosmologia: ensaios sobre o renascimento [online]. São Bernardo do Campo, SP: Editora UFABC, 2017, pp. 115-132. ISBN: 978-85-68576-93-9. https://doi.org/10.7476/9788568576939.0007.

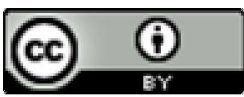

All the contents of this work, except where otherwise noted, is licensed under a Creative Commons Attribution 4.0 International license.

Todo o conteúdo deste trabalho, exceto quando houver ressalva, é publicado sob a licença Creative Commons Atribição $\underline{4.0}$.

Todo el contenido de esta obra, excepto donde se indique lo contrario, está bajo licencia de la licencia $\underline{\text { Creative }}$ Commons Reconocimento 4.0 . 
Professora Adjunta do Curso de Filosofia da Universidade Federal de Alagoas - UFAL. Doutora em Filosofia pela Universidade Federal de Minas Gerais - UFMG, com estágio de doutoramento (doutorado sanduíche) pela École des Hautes Études en Sciences Sociales (EHESS-Paris, 2008-2009) e Pós-Doutorado (2013) pelo Departamento de Filosofia da Universidade de São Paulo - USP. Atualmente, coordena o Grupo de Trabalho: Ética e Filosofia Política do Renascimento da Associação Nacional de Pós-Graduação em Filosofia - ANPOF. Coordena o Grupo de Pesquisa Ética e Filosofia Política da UFAL e integra o Grupo de Pesquisa Res publica da UNIFESP/USP. 


\section{A VIRTU் DO GOVERNANTE MAQUIAVELIANO E A TRADIÇÃO DAS VIRTUDES CRISTÃS ${ }^{10}$}

Flávia Benevenuto

Pode-se pensar a originalidade da obra de Maquiavel de várias formas. Passa-se inevitavelmente pelo seu rompimento com a tradição. Este rompimento pode ser pensado por vias distintas, mas há de conduzir, quem desejar investigá-lo, ao reconhecimento da tradição. Assim, compreender a virtù, tal qual enunciava Maquiavel, pressupõe uma compreensão mínima das virtudes tradicionais. É certo não se tratar de um único termo, haja vista o emprego dos termos virtù e virtute em seus significados distintos na língua italiana. Entretanto, é a complexidade do primeiro nos textos do autor, assim como as especificidades do momento histórico vivenciado

\footnotetext{
${ }^{10}$ Esse texto reproduz trechos da minha dissertação, intitulada Virtù e valores no pensamento de Maquiavel. Ele constitui parte do resultado de um projeto que desenvolvo atualmente na condição de pesquisadora financiada pelo CNPq $\backslash F A P E A L$.
} 
por Maquiavel, que dão o primeiro tom das dificuldades do tema. Maquiavel, de fato, não é o primeiro a utilizar o termo virtù, que remonta aos antigos. Porém, há certa originalidade na forma em que emprega o termo. Neste trabalho, procuraremos investigá-la à luz da tradição, valendo-nos do termo virtude, próprio da tradição cristã, para identificar alguns indícios do rompimento das obras de Maquiavel com esta tradição, tratando, de modo especial, aspectos que contribuam para a compreensão da virtù.

Iniciamos por algumas circunstâncias particulares contextuais deste momento de transição. Trata-se, como é sabido, de um período marcado pela ampla difusão dos valores cristãos por um lado e, por outro, pela sobeja corrupção do clero. Mas estas não são as razões que despertaram o interesse de Maquiavel pelo assunto. Nada disso seria efetivamente importante, tomando-se o cerne do pensamento de Maquiavel, se essa tradição cristã não impusesse seus valores ao agir político. Assim, a tradição cristã parece interessar a Maquiavel na medida em que interfere na vida política e, nesse sentido, os valores próprios da tradição cristã são criticados na medida em que interferem de forma negativa na cena pública. Assim, apesar das passagens que criticam diretamente a Igreja, o principal elemento da crítica diz respeito à política e à ação dos homens na cidade.

$\mathrm{Na}$ tentativa de evidenciá-lo, partimos de uma passagem dos Discursos sobre a primeira década de Tito Lívio ${ }^{11}$, na qual o autor acusa diretamente a Igreja pela fragmentação política e infidelidade do povo. Segundo ele,

\footnotetext{
${ }_{11}$ As seguintes abreviaturas serão usadas para a obra Discursos sobre a primeira década de Tito Lívio: 1. Discorsi, quando no texto; 2. Quando em nota no corpo do texto ou como referência bibliográfica, entre colchetes após o ano referente da edição utilizada, usaremos $\mathrm{D}$, seguida do livro e do capítulo.
} 
[...] nós, italianos, temos para com a Igreja e os padres essa primeira dívida, que é a de termos tornado sem religião e maus; mas temos ainda outra dívida, e maior, que é a segunda razão de nossa reina. É que a Igreja manteve e mantém essa terra dividida (MAQUIAVEL, 2007 [D I, 12], p. 233).

Em outra passagem, no terceiro capítulo d'O Príncipe ${ }^{12}$, Maquiavel aponta o papel negativo que a Igreja exercia na política de seu tempo. Afirma que

[...] quando Valentino ocupava a Romanha, dizendo-me ele que os italianos não entendiam de guerra, expliquei-lhe que os franceses não entendiam nada de Estado, pois se entendessem não teriam consentido à Igreja tamanha grandeza (MAQUIAVEL, 2004, [P III], p.126).

As passagens se fazem interessantes pelo ataque direto à Igreja, mas, e especialmente, pela acusação da divisão da Itália. De fato, o problema que Maquiavel identifica na religião de seu tempo diz respeito mais às suas consequências políticas do que aos seus preceitos religiosos propriamente ditos. Dizendo de outro modo, a crítica à Igreja é sem dúvida contundente e não se trata de minimizá-la aqui. Apenas de apontar que não se trata de uma denúncia da religião em um sentido mais amplo.

Maquiavel reconhece a importância da religião para a unidade do corpo político. Sua crítica recai sobre a corrupção. Neste sentido, abre o capítulo XII dos Discorsi afirmando justamente que

12 Para referenciar a obra O Príncipe, usaremos a abreviatura P, seguida do capítulo entre colchetes, após o ano da edição utilizada nas referências bibliográficas em nota no corpo do texto. 
[...] os principados ou repúblicas que queiram manter-se incorruptos devem, acima de tudo, manter incorruptas as cerimônias de sua religião e venerá-las sempre; porque não pode haver maior indício da ruína de um estado do que o desprezo pelo culto divino (MAQUIAVEL, 2007, [D I, 12], p. 52).

O uso do termo corrupção aqui ultrapassa a corrupção do clero. De fato, o problema que Maquiavel vê na religião não se configura como um problema propriamente religioso. Trata-se, principalmente, de um problema político. Esta forma de perceber a crítica maquiaveliana se justificaria pelas especificidades da tradição cristã, visto que ela eleva valores como o desdém pelas coisas do mundo, a punição numa esfera pós-morte e o perdão, influenciando de forma negativa o agir político.

A tradição, nos tempos de Maquiavel, marcada pelos preceitos cristãos, encerrava nos homens valores bem distintos dos que elevaram à glória os antigos pagãos. A virtude, conjunto de qualidades cristãs, é pensada por Maquiavel como aquela que enfraquece o homem, tornando-o covarde, medroso, passivo aos acontecimentos. Ela, nesse sentido, caracteriza-se como aquilo que há de mais inadequado a um homem de ação, a um homem que pretenda desenvolver um agir no Estado, voltado, por sua vez, para o bem comum. Por causa disso, Maquiavel sugere, em substituição à virtude, qualidades menos ideais, mas que, justamente por isso, resolveriam com maior êxito os problemas do mundo dos homens, mais especificamente de seu âmbito político. Para este tipo de questão, a tradição cristã não serviria para elevar os valores dignos de um homem de ação voltado para a lógica da eficácia. Elevaria antes a humildade, a fraqueza, a covardia, e foi nesse sentido 
que se tornou alvo das críticas do secretário florentino. Esses valores poderiam prejudicar o agir político e, neste caso, seria necessário substituí-los por aqueles capazes de trazer força, poder e glória. Seria necessário substituir tais valores por outra perspectiva, mais especificamente pela virtù. Ela é a única capaz de interpretar a veritá effetuale e concretizar os objetivos daquele que governa, em especial, "conquistar e manter o poder", seguidos pela "durabilidade" do corpo político, e ainda, por sua "grandeza".

Sabemos então que, para Maquiavel, o governante de virtù empenha-se nestes objetivos. Ao praticar suas ações, no entanto, não necessariamente as regula por um fator externo a este objetivo, agindo assim em função das imposições das contingências que passam a ser, em grande medida, a referência das dificuldades a serem superadas para garantir a efetividade de tais objetivos principais. Esta reflexão, a que nos conduz o autor, passa necessariamente pela análise da percepção que se tem das ações praticadas pelo governante de virtù. O êxito da efetividade de suas ações depende, em parte, da maneira como suas ações são percebidas. Esta percepção se efetiva, por sua vez, mediante parâmetros morais que predeterminam uma dada expectativa da ação tal como ela deve ser. O âmbito da política não é transparente nem aos olhos do povo nem aos dos grandes, e consequentemente, não é transparente também aos olhos dos atores políticos. Não se desvela a ninguém. Ao mesmo tempo que o governante precisa (ao menos) manter-se no poder, e para isso precisa ser um homem de virtù e guiar-se por ela, ele convive sempre com outra lógica da ação. Lógica essa que traça determinadas expectativas em relação a tudo o que ele faz.

É interessante notar que Maquiavel não se interessa pela essência desses problemas que são, acima de tudo, de ordem 
metafísica ou teológica. E, quando a eles recorre, parece fazêlo para solucionar questões que estão em outro plano, ou seja, para encontrar soluções que dizem respeito à cena pública, à política. Ou ainda, o interesse de Maquiavel está nas consequências que trazem estes conceitos. Nesse sentido, poderíamos dizer que os conceitos desses filósofos que constituem o pensamento clássico cristão não são eles mesmos o objeto de Maquiavel. Influenciam muito mais enquanto acabam por interferir nos valores que constituem o Estado. Este é o sentido no qual as concepções de uma ordem externa à política interessam Maquiavel. Partindo dessa perspectiva, o cristianismo seria o responsável pelas modificações que ele observava nos homens. O paganismo trazia já em seus rituais a crueldade, ou ainda "engendrava a ferocidade pela magnificência de seus sacrifícios [...] celebrava esse mundo, desafiava a glória política" (COLONNA D'ISTRIA; FRAPET, 1980, p. 164). A tradição pagã acabava por criar, ela mesma, condições propícias a despertar no homem uma valorização da ação. Nesse sentido, a religião cumpria o papel que, de acordo com Maquiavel, cabe a todas as religiões, de valorizar as virtudes populares (COLONNA D'ISTRIA; FRAPET, 1980, p. 164-166). No caso do paganismo, a ação é que trazia glória, a coragem e a potência, que por sua vez, tinham realmente valor.

$\mathrm{O}$ incentivo à ação acabou por fundar, ainda na Era Pagã, uma tradição que impulsionava o agir justamente no mundo dos homens. Essa tradição de valorização da ação política, muito difere daquela que foi consolidada pela tradição cristã, que, por sua vez, promove justamente os valores contrários à vida ativa. Ou ainda, tal como afirmam D'Istria e Frapet,

[...] o cristianismo glorifica os humildes, a vida contemplativa, a impotência a agir. Ele exalta a saudação 
individual rebaixando os valores do homem comum, ele fecha o indivíduo na esfera dos limites da vida privada (COLONNA D'ISTRIA; FRAPET, 1980, p. 164).

Ela eleva os valores “errados”, os valores contrários à ação e, por isso mesmo, impróprios à vida política. Os valores que agora trazem "glória" (dos céus) são a humildade, a caridade, a retidão; por meio, especialmente, do ócio! A promoção dessa profunda transformação dos valores, assim como suas consequências no que diz respeito à ação política, parece conduzir Maquiavel a uma crítica contundente da tradição cristã.

De acordo com os autores,

[...] o cristianismo foi mal interpretado enquanto religião em geral; é o azar dos tempos que quer que o cristianismo seja "nossa religião". Seria necessário saber interpretá-lo assim como os antigos souberam interpretar sua religião, o paganismo (COLONNA D'ISTRIA; FRAPET, 1980, p. 166).

Mas, mesmo "bem interpretada", a religião do tempo de Maquiavel não valorizava a ação política. Seus valores muito se diferenciavam dos da antiga religião pagã. Humildade, bondade e caridade, por exemplo, pouco favorecem a defesa do corpo político pela guerra, por exemplo. Sua exigência pelo ócio contemplativo certamente produzia entraves à ação política. Deste modo, os valores que o cristianismo se esforça para infundir nos homens são contrários àquilo que é necessário para se obter êxito no agir político. A ideia ainda de que a Providência Divina controla tudo, todas as coisas do mundo, esvazia de sentido o agir político na vida terrena. Assim como afirma Pocock, "o cristianismo leva os homens a outros fins que não às cidades e a amar suas almas mais que sua própria 
terra” (POCOCK, 1975, p. 202). Ao transferir o que é realmente relevante para a "cidade celeste", e introduzir o ócio contemplativo como meio terreno para alcançá-lo, retira-se do agir político sua função própria. Resta apenas ser virtuoso e contemplar, pois a contemplação é capaz de nos aproximar da perfeição divina, enquanto o agir político, trabalhoso e perpassado por toda sorte de contingências, não passaria de perda de tempo.

Uma vez que o governante pretende efetivar os objetivos que lhe são próprios e que sua ação deve ser determinada pela sua virtù, e dado ainda que não necessariamente a virtù o guiará pelos caminhos delimitados pela moralidade vigente, não há garantias, consequentemente, de que a moralidade vigente deva ser tomada pelo governante da mesma maneira que pelos demais integrantes do corpo político. Uma vez que os valores morais do tempo de Maquiavel são determinados em grande medida pelas virtudes cristãs, há um descompasso entre o agir "virtuoso" e a ação de virtù. Assim, dado que Maquiavel nos põe a pensar o governante de virtù como um imperativo para a manutenção do poder do corpo político, ele, consequentemente, nos conduz a pensar também sobre as dimensões da moralidade no âmbito da política.

Podemos pensá-la, particularmente, a partir do reconhecimento da distância existente entre como deveríamos viver e como de fato vivemos, mas sugere se interessar mais pelas consequências desta distância. Em uma passagem famosa de sua obra $O$ Príncipe, ele afirma que "há tamanha distância entre como se vive e como se deveria viver, que aquele que trocar o que se faz por aquilo que deveria fazer aprende antes a arruinar-se que a preservar-se" (MAQUIAVEL, 2004 [P XV], p. 159). A conclusão de Maquiavel evidencia sua preocupação 
com a manutenção do poder, ao mesmo tempo que anuncia que o "dever-ser" - que neste caso se fundamenta nos valores morais cristãos de seu tempo - não necessariamente se caracteriza como o ponto de partida das ações do governante. Isto significa que, para manter-se no poder, o governante precisa se inserir em uma lógica de valores mais flexível e igualmente mais capaz de integrar-se às necessidades mais iminentes do corpo político. Trata-se, antes de tudo, do reconhecimento da política no âmbito da aparência. Mais que isso, do reconhecimento de que o mundo dos homens é marcado pela contingência. Ele pode possibilitar a substituição de ações antes exclusivamente presas à tradição, à moralidade cristã, por uma lógica de maior propensão à durabilidade no tempo e que se prende somente àquilo que se faz necessário a cada instante.

Precisamos, no entanto, refletir um pouco mais sobre este rompimento com os valores da tradição e as possibilidades morais do governante. De fato, o governante é julgado por aqueles que integram o corpo político de acordo com os valores morais incorporados pela tradição. Em outras palavras, podemos dizer que há uma moralidade própria ao corpo político. Há, consequentemente, uma expectativa da concordância das ações daqueles que o compõem com um determinado modelo moral e, neste sentido, há também uma espécie de modelo de ação a ser efetivada. A questão difícil de ser resolvida diz respeito justamente à figura do governante, pois dele se espera o mesmo comprometimento assumido pelo corpo político com o que deve ser feito. Maquiavel, no entanto, nos conduz a questionarmos tal possibilidade. Pode o governante agir integralmente segundo esta expectativa do que deve ser feito? Já sabemos que não. Sabemos que agindo deste modo encontraria antes a ruína que os meios para se conservar no 
poder. Mas a questão seguinte parece ser mais comprometedora. Ao praticar aquilo que se faz necessário para manter o poder em vez de comprometer-se efetivamente com as ações que seriam apropriadas à moralidade vigente, o governante assume definitivamente o lugar da imoralidade?

A resposta a estão questão pode ser sim, se tomamos a pergunta a partir do rompimento definitivo do ator político com a tradição cristã como aquilo que diz respeito aos pressupostos que ele precisa assumir para efetivar suas ações e conservar seu poder; e não, se pensamos que a moralidade cristã não encerra todas as possibilidades de se pensar a moralidade política. Maquiavel, no entanto, parece buscar a superação desta questão apelando para a verdade efetiva. Ele, de fato, não se prende às qualidades "desejáveis". O critério é outro, refere-se muito mais à manutenção do governo. O "dever-ser" é substituído pela "lógica da necessidade"13 e, nesta lógica,

[...] encontrar-se-ão coisas que parecem virtù e que, se fossem praticadas, lhe acarretariam a ruína, e outras que poderão parecer vícios e que, sendo seguidas, trazem segurança e o bem-estar do governante (MAQUIAVEL, 2004 [P. XV], p. 160).

A este ponto já há elementos para se considerar que as "coisas" que parecem virtù são justamente as virtudes cristãs. ${ }^{14}$

\footnotetext{
${ }_{13}$ Necessidades imediatas ou, para usar um termo mais apropriado para a filosofia, contingências. No que diz respeito à política, nem tudo se resume às contingências, como se procurará mostrar mais adiante. Porém, estas últimas podem ser definitivas e, por isso, ocupam um lugar importante no pensamento de Maquiavel.

14 As qualidades apontadas como tais pela "moral" cristã encontram-se explícitas, em especial, no Gênero dos Specula (enquanto conceito) e na análise que Maquiavel faz do caso Savonarola (enquanto tentativa de ação).
} 
Essas virtudes podem ser praticadas (e devem-no, haja vista que a moralidade vigente se expressa pelos valores da tradição cristã). Porém, sua prática faz-se interessante apenas enquanto não prejudica assuntos propriamente políticos, como a manutenção do corpo político, por exemplo. Vê-se bem na afirmação de Maquiavel que a lógica a ser seguida não é a que se define pela dicotomia entre virtudes e vícios. O critério, como dissemos, define-se muito mais nas coisas reais, na veritá effetuale, ou ainda, no que diz respeito à manutenção do Estado. Essa é a mudança de perspectiva proposta por Maquiavel. Assim, a veritá effetuale exige que a ação do governante ocorra seguindo as imposições contingenciais. É ela que, em grande medida, determina os parâmetros das ações de um governante capaz de conservar seu poder.

Não se pode pressupor que todas as ações humanas estejam restritas às contingências. As obras de Maquiavel não nos conduzem a esta conclusão. Ao escrever conselhos ao governante, e dedicar-se exaustivamente à História, o autor parece ocupar-se justamente daquilo que se pode prospectar, esperar, enfim, produzir expectativa no âmbito da política. Há de se reconhecer, no entanto, e o texto de Maquiavel o demonstra igualmente, que parte das coisas diz respeito à fortuna. Não se pode prever o futuro. Da fortuna, a única coisa que se pode ter certeza, é que introduzirá mudanças. Patrícia Aranovich nos ajuda a compreender a questão. Ao comentar o Di Fortuna de Maquiavel, ela acaba por apresentar a complexa relação entre aquilo que pode ser tomado como constante na obra de Maquiavel e aquilo que é tomado como inconstante para o autor.

A incompatibilidade deriva, justamente, da natureza humana e da natureza da Fortuna. A natureza do homem é constante, assim como o são o céu, o sol e os 
elementos. Os homens foram e são sempre os mesmos, dotados dos mesmos humores e paixões; e cada homem nasce dotado de um determinado engenho e fantasia que permanecem constantes durante toda sua vida. A fortuna é constantemente inconstante: é de sua natureza ser volúvel e móvel. Essa incompatibilidade provoca a ruína dos que se deixam levar por ela e daqueles que não lhe opõem obstáculos (ARANOVICH, 2011, p. 221-222).

A passagem suscita o debate de dois temas que não constituem propriamente o objeto da nossa análise, mas que contribuem para que possamos compreender que, ao pensar as ações humanas a partir de Maquiavel, precisamos considerar que se inscrevem em duas ordens distintas. Uma delas diz respeito ao que é propriamente humano; a outra, ao que diz respeito ao acaso. Pressupondo-as em suas diferenças, destaca-se o lugar das contingências nas coisas humanas e, especialmente nos assuntos públicos. Pressupor este lugar, no entanto, não implica dizer que tudo se reduz à mera contingência, mas, e apenas, que ela é uma parte importante a se considerar quando tratamos as possibilidades das ações humanas no âmbito da política. Mesmo aquilo que se pode prospectar e esperar, não se pode prever e considerar como certo e definitivo. A fortuna pode intervir a qualquer momento, em toda sorte de ação política. É neste sentido que se faz necessário reconhecer que a política se inscreve no âmbito da contingência.

O problema é que, pensar as ações humanas a partir de imposições contingenciais e agir de acordo com o que exigem as circunstâncias, inviabiliza a construção de um "modelo" a ser seguido. Assim, como não é possível, nem mesmo por meio dos "modelos" antigos e modernos aos quais se referia Maquiavel, construir um "modelo" totalmente determinado para 
guiar as ações humanas que dizem respeito às coisas públicas (POCOCK. 1975, p. 18). Pensar a questão da ação política a partir do pensamento de Maquiavel nos conduz, assim, a identificar a impossibilidade de criação de um modelo acabado a ser oferecido àquele que governa. De fato, os ensinamentos de Maquiavel não pressupõem e nem poderiam constituir um modelo determinado para conduzir as ações do governante. Implicam antes a descoberta da complexidade do real, a complexidade que envolve a ação humana e a dificuldade de lidar com as consequências dessa ação no âmbito da política tal como ele é, caracterizado pela aparência. Essas considerações apontam o registro das obras de Maquiavel, caracterizado, especialmente, por considerar as ações políticas capazes de se efetivar na história, evitando assim aquelas que se distanciam da veritá effetuale. A "verdade efetiva", no entanto, tomada como um critério-guia em relação às ações que o governante deve efetivar, provoca, inevitavelmente, o enfrentamento direto da tradição.

Devemos observar, juntamente a Claude Lefort, ${ }^{15}$ que não é Maquiavel quem cria esta distinção. Ele apenas a identifica, apenas reconhece sua existência. A partir do momento em que confere pouca importância a "modelos que nunca existiram", torna-se de certa forma enunciador da verità effetuale. Nesta verdade efetiva, há uma distinção substancial entre o que deve ser feito e o que se faz. Maquiavel exime-se do julgamento da questão. Em vez de defender o que se deveria fazer e se posicionar contra o que se faz, prefere assumir tal dicotomia como característica da realidade como um todo. Assim, não hesita em afirmar: "parece-me mais conveniente

${ }^{15}$ LEFORT. Desafios da Escrita Política. São Paulo: Discurso, 1999. p. 141-177. 
procurar a verdade efetiva das coisas do que o que se imaginou sobre elas" (MACHIAVELLI, 1997, XV, p. 159). O autor, assim, escolhe como objeto de sua investigação somente exemplos que já se efetivaram. Ele se propôs a tratar daquilo que se efetivou na história, abandonando de forma definitiva o que fora eventualmente imaginado pelos homens ${ }^{16}$.

De fato, as circunstâncias em que se insere a vida humana são variadas e não necessariamente é possível conhecer previamente as consequências das ações humanas. A impossibilidade de se preverem as condições das ações futuras, assim como as consequências das ações presentes, parece impelir Maquiavel a considerar os imprevistos. Assim, se, por um lado, circunstâncias favoráveis possibilitam ao governante efetivar determinadas ações, elas podem, por outro, ser adversas e dificultar, ou mesmo impossibilitar, o sucesso esperado como resultado da prática de outras. A imprevisibilidade das

16 Talvez aqui tenhamos encontrado uma distinção mais definitiva no que diz respeito à comparação d'O Príncipe com os Specula. Enquanto no caso destes últimos o governante deve se guiar em geral pelo dever-ser, O Príncipe parece sugerir uma postura um pouco distinta. Não se trata, assim, de suprimir esta dicotomia no âmbito teórico, mas de ultrapassá-la pela opção pela efetividade do que Sfez chama de "política do meio mal". Não podemos pensar, entretanto, que a peculiaridade da obra de Maquiavel, ao identificar o espaço da política como coincidente com o da aparência, se caracteriza como uma consequência exclusiva das distinções que apresenta em relação aos manuais tradicionais de aconselhamento para príncipes. Nem tampouco que ele encerra sua análise sobre as possibilidades das ações do governante para conquistar e manter o poder, assim como sobre a variação das circunstâncias que lhe são próprias. Há outros elementos apontados por Maquiavel que ainda não foram tratados em nosso trabalho. Uma vez analisados a divisão do corpo político e o conflito inevitável entre suas partes, assim como o ambiente deste corpo político que é caracterizado pela aparência, resta-nos ainda investigar o elemento que impõe ao corpo político a maior parte das variações de suas circunstâncias (algumas vezes já mencionado no presente capítulo, mas ainda não investigado). Em outras palavras, resta-nos ainda analisar a fortuna, elemento capaz de introduzir modificações nas circunstâncias em que o governante deverá efetivar suas ações. 
consequências das ações do governante no interior do espaço público é tratada por Maquiavel em grande medida nos capítulos em que ele apresenta as dificuldades impostas pela fortuna. Essa última, ao modificar as circunstâncias, exige que o governante desenvolva sua capacidade de improvisar. Improvisar para minimizar a rispidez dos infortúnios ou para aproveitar a talvez efêmera bonança. Esta capacidade é, de modo geral, denominada virtù. E, como se procurou mostrar aqui, muito se diferencia das virtudes cristãs. Se estas últimas, uma vez empregadas amplamente nos assuntos da política, poderiam conduzir o governante, e mesmo o corpo político à ruína; a virtù, tal como apresentada por Maquiavel, seria a única possibilidade de reverter um quadro circunstancial inadequado aos objetivos do governante, ou dos indivíduos. A via mais segura para promover os principais objetivos do governante, relacionados à conquista, à manutenção do poder, à grandeza e à durabilidade do corpo político.

\section{Referências}

ARANOVICH, Patrícia. Di Fortuna e a Fortuna em Maquiavel. In: Cadernos de Ética e Filosofia Política. 18, 1, p. 221-230, 2011.

COLONNA D'ISTRIA, Gerard; FRAPET, Roland. LAArt Politique chez Machiavel. Paris: J. Vrin, 1980.

LEFORT, Claude. Desafios da Escrita Política. Tradução de Eliana de Melo Souza. São Paulo: Discurso, 1999.

MACHIAVELLI. Discorsi. In: MACHIAVELLI, Opere. Torino: Einaudi-Gallimard, 1997. v. 1. 
. Il Principe. In: MACHIAVELLI, Opere. Torino: Einaudi-Gallimard, 1997. v. 1.

MAQUIAVEL. O Príncipe. São Paulo: Martins Fontes, 2004.

MAQUIAVEL. Discursos sobre a Primeira Década de Tito Livio. São Paulo: Martins Fontes, 2007.

POCOCK, J. G. A. The Machiavellian Moment. Princeton: Princeton University Press, 1975.

SFEZ, Gérald. Machiavel, la politique du moindre mal. Paris: Presses Universitaires de France, 1999. 